\title{
Type 1 procollagen as a marker of severity of scarring after sternotomy: effects of topical corticosteroids
}

\author{
Y Riaz, H T Cook, A Wangoo, B Glenville, R J Shaw
}

\begin{abstract}
Aims-To determine whether the abundance of newly formed collagen in healing surgical wounds correlated with scar severity, and whether topical application of steroid cream reduced new collagen formation in patients who have undergone median sternotomy.

Methods-Thirty three patients six weeks after sternotomy, and 12 controls were studied. Scars were photographed, and biopsy specimens from scars at sites treated or untreated with topical corticosteroids (clobetasol proprionate $0.5 \%$ ) were examined using immunohistochemical staining for type 1 procollagen (PCP 1) and transforming growth factor $\beta$ (TGF- $\beta$ ), and in situ hybridisation for type 1 procollagen messenger RNA (mRNA).
\end{abstract}

Results-The degree of hypertrophy of the scar and the abundance of PCP 1 immunostaining were ranked independently, blind, and a correlation between these two variables was observed $(r=$ 0.604 , $p<0.001)$. The PCP 1 immunostaining was accompanied by a great abundance of PCP $1 \mathrm{mRNA}$ and only a slight increase in TGF- $\beta$ immunostaining, when compared with normal skin or mature scars. Following the application of topical corticosteroids, for either 48 hours or twice daily for seven days, there was no reduction in PCP 1 immunostaining nor the abundance of PCP 1 mRNA.

Conclusions-These data suggest that the extent of new collagen formation as assessed by PCP 1 immunohistochemistry may be a useful marker of the exuberance of the scarring process following sternotomy, and that topical corticosteroids are ineffective in reducing this component of the fibrotic response.

(f Clin Pathol 1994;47:892-899)

After surgery, optimal healing combines rapid development of a scar with high tensile strength but this is minimally disfiguring. Hypertrophic, or in extreme cases keloid scars, are an overexuberent response to skin injury. This often occurs after sternotomy, ${ }^{12}$ causing discomfort, pruritis, and occasionally further plastic surgery. ${ }^{2} \mathrm{~A}$ variety of different approaches have been used in an attempt to prevent the development of hypertrophic scars, but these have rarely been linked to individual components of the pathophysiology of hypertrophic scar formation. The development of a scar involves the influx of inflammatory cells into the wound, and the production of growth factors for fibroblasts, such as transforming growth factor $\beta$ (TGF- $\beta$ ) ${ }^{3}$ In response to these, fibroblasts migrate into the wound and synthesise collagen. ${ }^{45}$ Initially, type III collagen is the principal collagen synthesised, but this is gradually replaced by type I collagen. ${ }^{36}$ Later, collagen remodelling and cross-linking take place. ${ }^{7}$ This process is exaggerated in hypertrophic scars where there is evidence of excessive collagen deposition. ${ }^{45-10}$ Type I collagen is a triple helix composed of two $a_{1}$ and one $a_{2}$ chains. ${ }^{11}$ Because type I procollagen carboxyl and amino terminal domains are proteolytically removed during collagen secretion, ${ }^{45}$ antibodies to these domains have been used to stain fibroblasts synthesising type I collagen. ${ }^{12}$ The use of immunocytochemistry with antibodies to the amino or carboxyl terminal ends of each $a$ chain of procollagen peptide 1 (PCP 1) and in situ hybridisation has allowed individual fibroblasts synthesising new collagen to be identified.

In this study, we examined sternal scars six weeks after sternotomy to seek evidence of new collagen formation at this stage of established scar formation, and to determine if the extent of new collagen formation correlates with the macroscopic appearance of the scar. We asked if topical corticosteroids, agents long thought to prevent progression of keloid scars, ${ }^{13}$ and now recognised to reduce collagen production in vitro, ${ }^{14}$ have the ability to reduce the biochemical markers of new collagen production in these healing surgical wounds. Furthermore, the abundance of the growth factor TGF- $\beta$ in the scars was also measured.

\section{Methods}

Thirty three patients were recruited four to eight weeks after cardiothoracic surgery involving a sternotomy. A further eight patients were recruited before surgery, to provide samples of healthy skin. Four patients who had had surgery over a year ago were also recruited to provide samples of mature scar tissue. Informed written consent was obtained. Approval for this study was granted by the Parkside Health Authority Ethics Committee.

At the initial visit, the sternotomy scars were examined to exclude any patients who 
had had infection or dehiscence of the wound. A photograph was taken of the lower $5 \mathrm{~cm}$ of the scar with a Nikon FM camera with a 105 $\mathrm{mm}$ Micro-Nikkor lens at $0.7-0.55$ magnification, on Kodak Ektar 25 ASA colour film. Lighting was enhanced using a Sunpack Auto 28SR Thyristor flash gun.

An area $3 \mathrm{~cm} \times 3 \mathrm{~cm}$ was marked out at the lower end of the sternotomy scar, using a permanent marker pen. A small amount of Dermovate (clobetasol proprionate $0.05 \% \mathrm{w} / \mathrm{w}$ ) was gently massaged into the scar within this area. Eight patients had a single application of steroid cream, covered with a Tegaderm dressing, and were asked to return 48 hours later. The other 25 patients were asked to apply the cream, within the marked area only, twice a day for seven days.

Two samples of scar tissue were obtained from each patient. The first was from within the marked area (where the steroid based cream had been applied) and the second sample was from an adjacent area of the scar where cream had not been applied. The biopsy specimens were taken under local anaesthesia ( $1 \mathrm{ml}$ of $1 \%$ Lignocaine, in adrenaline 1 in 200000 , injected subcutaneously) using a $3 \mathrm{~mm}$ biopsy punch (Stiefel Laboratories (UK) Ltd., Wooburn Green, Bucks, England). The steroid and non-steroid scar samples were fixed separately in formolsaline, embedded in paraffin wax, and cut into sections that were mounted onto poly-Llysine slides. Routine haematoxylin and eosin staining was performed to assess cellularity and the extent of scar formation.

\section{IMMUNOHISTOCHEMISTRY}

Sections 3-4 $\mu \mathrm{m}$ thick were cut from each biopsy specimen, dewaxed, and treated with $3 \%$ hydrogen peroxide in methanol to quench the activity of endogenous peroxidase. The sections were rehydrated in phosphate buffered saline (PBS) ( $\mathrm{pH} 7 \cdot 2$ ) and were digested with trypsin (0.5\% trypsin and $0.5 \%$ chymotrypsin; Sigma) for 10 or 20 minutes before immunostaining for type 1 procollagen and TGF- $\beta$, respectively. Non-specific protein binding was blocked with 1 in 5 normal porcine serum (Dako Ltd., High Wycombe, Bucks) in PBS. Primary antibodies used in this study were polyclonal rabbit anti-human procollagen -1 (Gift from. M J Warburton, St George's Hospital Medical School, London) ${ }^{15}$ and TGF- $\beta$ (British Biotechnology Products Ltd., Oxon, England). The antibodies were diluted in 1 in 20 porcine serum in PBS. The sections were incubated with the optimal dilution of the primary antibodies ( 1 in 400 for type 1 procollagen and 1 in 100 for TGF- $\beta$ in PBS) for one hour in a humidifying chamber at room temperature. The sections were washed with PBS and incubated with biotinylated goat anti-rabbit antibodies (Dako Ltd.) for 30 minutes, washed, and then incubated with avidin biotin peroxidase complex (Dako Ltd.), washed for 15 minutes, and visualised with 3,3'-diaminobenzidine (DAB) substrate (Dako Ltd.). The sections were counterstained with Mayer's haematoxylin solution
(Sigma Diagnostics, St Louis, Missouri, USA) for one minute. In control sections, specificity was ascertained when the primary antibody step was omitted or replaced with purified normal rabbit serum (Dako Ltd.).

\section{IN SITU HYBRIDISATION}

The procedure for in situ hybridisation was modified from methods described earlier. ${ }^{16}$ Briefly, 3-4 $\mu \mathrm{m}$ sections were cut from skin biopsy specimens embedded in paraffin wax and were mounted on Vector bond (Vector Laboratories, Burlingame, California, USA) coated slides and baked overnight at $56^{\circ} \mathrm{C}$. Tissue sections were dewaxed and rehydrated through an alcohol series to PBS. Sections were treated with proteinase $\mathrm{K}$ (Boehringer Mannheim UK) $50 \mu \mathrm{g} / \mathrm{ml}$ for seven and a half minutes, washed in PBS, followed by acetylation with $0.1 \%$ acetic anhydride in $0.1 \mathrm{M}$ triethanolamine to reduce non-specific interaction between DNA probes and tissue. Slides were washed in PBS, dehydrated, and air dried and used for hybridisation on the same day or stored at $-20^{\circ} \mathrm{C}$.

For type 1 procollagen, two 27 base synthetic DNA oligonucleotide anti-sense sequences were made to order (British Biotechnology UK) to be used as probes. The sequences were (1) 5'-ACC AGT CTC ACC ACG ATC ACC ACT CTT-3' [-366 to -392] (2) 5'-TCC CTT AGC ACC AGT GTC TCC TTT GCT-3' [-2229 to -2255] and were deduced from the published DNA sequence of the human pro $a$ (1) chain of human type 1 procollagen. ${ }^{17} \mathrm{~A}$ cocktail of both oligonucleotides was 3'-end labelled with deoxyadenosine $5^{\prime}-\left(a-{ }^{35} S\right)$ thiotriphos (Amersham International plc., Bucks, England). The reaction consisted of $10 \mathrm{pM}$ of each oligonucleotides, $8 \mu \mathrm{l}$ of $5 \times$ buffer (Promega Corporation, Madison, USA), $4 \mu \mathrm{l}$ of terminal deoxynucleotidyl transferase enzyme (Amersham UK), $5 \mu \mathrm{l}$ of ${ }^{35} \mathrm{~S}$ (dATP) and $18 \mu \mathrm{l}$ of deionised water to make a total of $40 \mu \mathrm{l}$. The reaction was incubated at $37^{\circ} \mathrm{C}$ for one hour and $3^{\prime}$ end labelled probes were purified using NENSORB Nucleic acid purification cartridge (NEN Du Pont (UK) Ltd) according to the manufacturer's recommendations. ${ }^{18}$

Tissue sections were overlaid with $100 \mu \mathrm{l}$ of hybridisation buffer which consisted of a $50 \%$ solution of formamide (Sigma), $1 \times$ Denhardt's solution, $1 \mathrm{mM} / 1$ EDTA, 100 $\mu \mathrm{g} / \mathrm{ml}$ denatured herring sperm DNA, 250 $\mu \mathrm{g} / \mathrm{ml}$ yeast tRNA, $10 \mathrm{mM}$ phosphate buffer, $10 \%$ dextran sulphate and $4 \times$ sodium chloride/sodium citrate (SSC). Before use, hybridisation buffer was heated to boiling for five minutes and quenched on ice, and 250 $\mu \mathrm{g} / \mathrm{ml}$ polyadenylic acid and $10 \mathrm{mM} / 1$ dithiothreitol was added. The ${ }^{35} \mathrm{~S}$ labelled oligonucleotide probes were diluted in hybridisation buffer to give between $20-30 \times 10^{6}$ counts per ml. Hybridisation was performed overnight at room temperature. After incubation, the sections were washed with several changes of $1 \times S S C$ at $54^{\circ} \mathrm{C}$ for one hour. After washing, slides were air dried and 
Figure 1 Variation in the severity of sternotomy scars six weeks following surgery: $(A)$ thin line scar; (B) mildly hypertrophic scar; (C) severely hypertrophic scar.
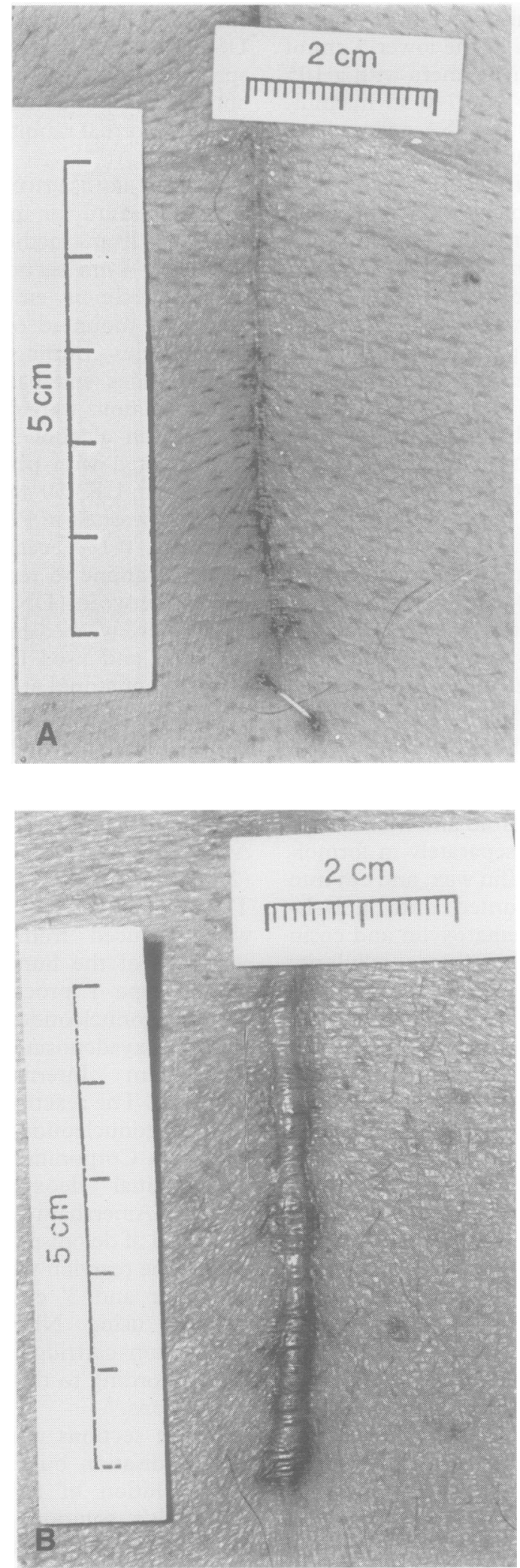

dipped in Ilford K5 nuclear track emulsion (Ilford Ltd. Mobberley, Cheshire, England). After an exposure period of two weeks, the sections were developed in Phenisol developer (Ilford Ltd.), fixed in $0.3 \mathrm{~mol} / 1$ sodium thiosulphate (BDH Ltd., Poole, Dorset, England), washed in deionised water, counterstained in Mayer's haematoxylin (Sigma) and mounted.

To serve as controls, some tissue sections were treated before hybridisation with 20

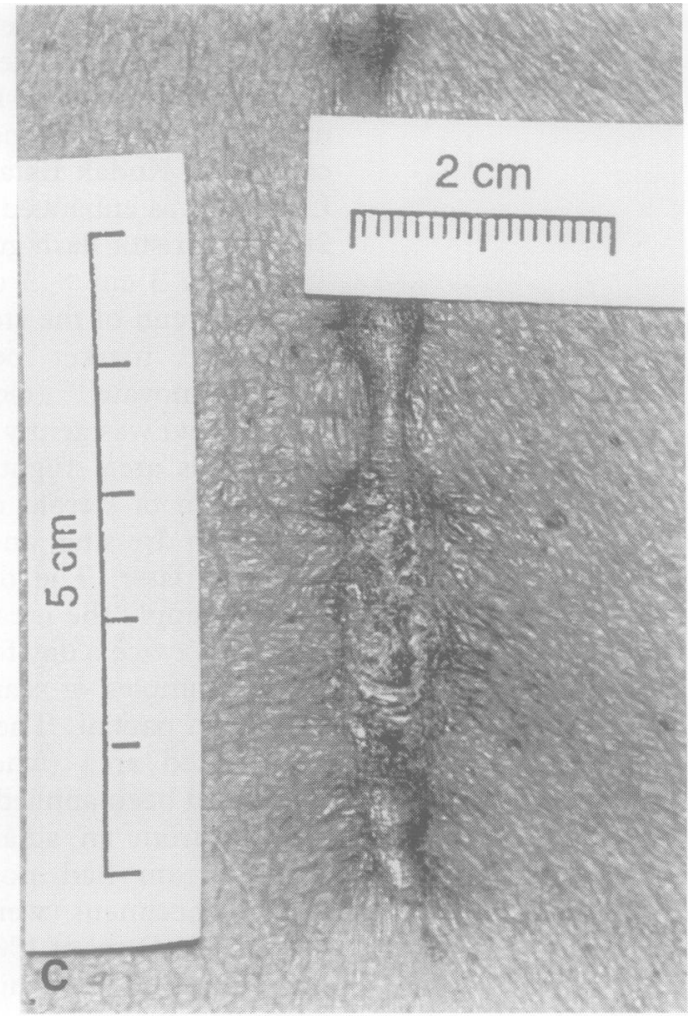

$\mu \mathrm{g} / \mathrm{ml}$ of ribonuclease A (Sigma, Poole, Dorset) and 80 Units $/ \mathrm{ml}$ of ribonuclease $\mathrm{T} 1$ in PBS at $37^{\circ} \mathrm{C}$ for 30 minutes. Other control slides were included to validate the specificity of the method. These included competition of the radiolabelled oligonucleotides with either the unlabelled probes used at a 50-fold excess ( $350 \mathrm{ng} /$ slide) or with a large excess $(10 \mu \mathrm{g}=1$ nmol/slide) of an unlabelled "irrelevent" oligonucleotide of similar $\mathrm{G}+\mathrm{C}$ composition $(47 \%)$. To verify further hybridisation specificity, slides from one case were probed with the irrelevent 30-mer which had been 3' tailed with ${ }^{35} \mathrm{~S}$ dATP.

\section{GRADING OF SCARS AND PCP}

Two observers (YR and HTC) independently ranked the photographs and the biopsy slides from each patient from 1-33, after PCP 1 immunostaining, according to severity of macroscopic scarring and extent of PCP 1 immunostaining. This ranking was performed in a coded manner, such that the photography and immunohistology results were assessed independently. The criteria used to assess the photographs of the scars were width of the scar and whether the scar was flattened or raised. The immunohistochemistry slides were analysed under the light microscope ( $\times 340$ and $\times 540$ magnification). In the part of the study comparing biopsy specimens from treated and untreated skin, paired samples were examined without knowledge of the code. The observers documented both the cellular and perivascular staining and graded according to the extent of staining on a scale of $0,+/-,+,++,+++$. The results from the two biopsy specimens (with and without topical steroids) were compared and a score was assigned to each pair according to whether application of steroid resulted in an 
Figure 2

Immunohistochemical staining of PCP 1 in scar tissue: $(A)$ six week old scar with intracellular and perivascular staining; (B) normal skin; (C) mature scar. Positive PCP 1 staining was detected by the brown deposition of $D A B$ precipitates. increase or a decrease in the degree of PCP 1 staining.

Spearman's rank correlation coefficient ${ }^{19}$ was used to test the correlation between the degree of PCP 1 staining and the severity of the scar. These differences in cellular PCP 1 staining in biopsy specimens from treated and untreated skin were analysed using the Wilcoxon sign rank test for paired observations.

\section{Results}

There was a wide variation in the visible appearance of sternotomy scars (fig 1). The scar appearances included thin line scars, mildly hypertrophic scars, and severely hypertrophic scars extending beyond the line of incision (figs $1 \mathrm{~A}-\mathrm{C}$ ).

Haematoxylin and eosin staining showed that the scars contained inflammatory cells and elastic van Gieson staining for mature collagen highlighted mature collagen fibrils. Immunohistochemical staining for PCP 1 identified both pronounced intracellular staining and perivascular staining (fig $2 \mathrm{~A}$ ). This compared to the low abundance of PCP 1 immunostaining of normal skin (fig 2B) and
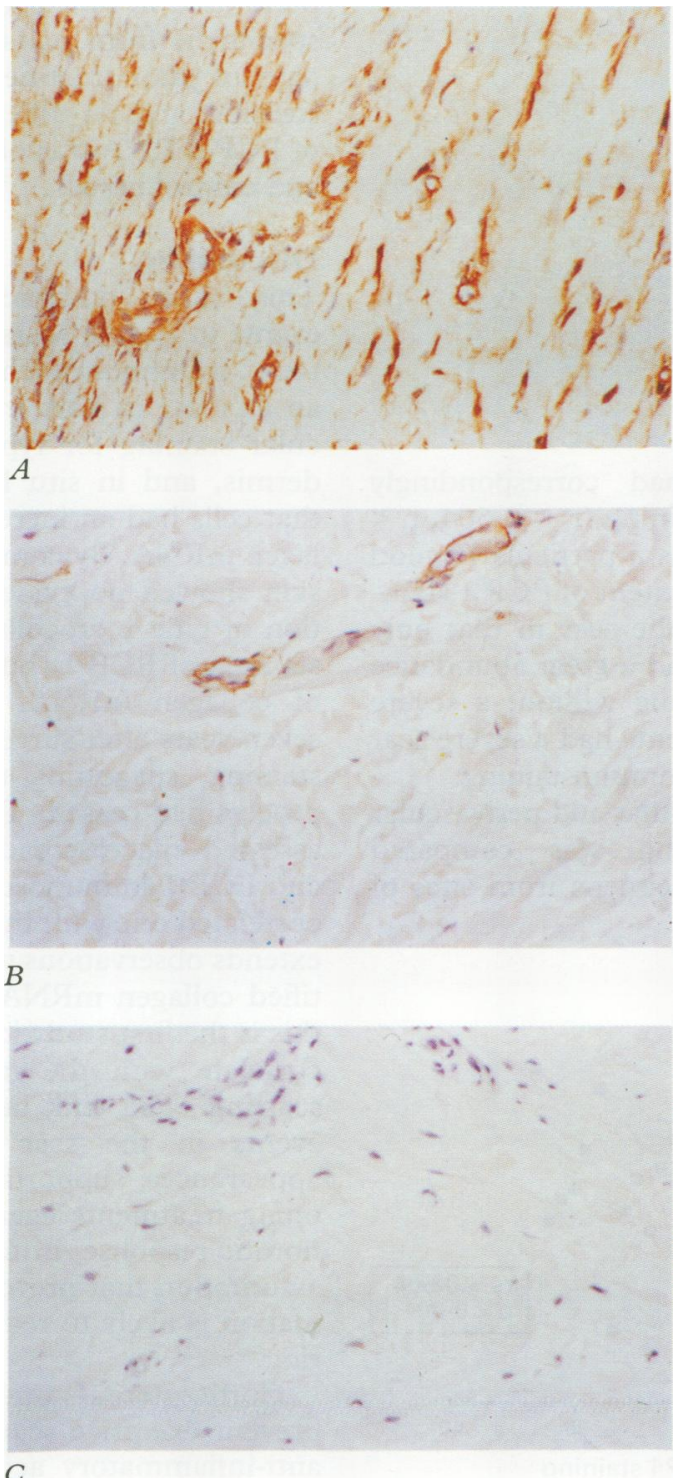

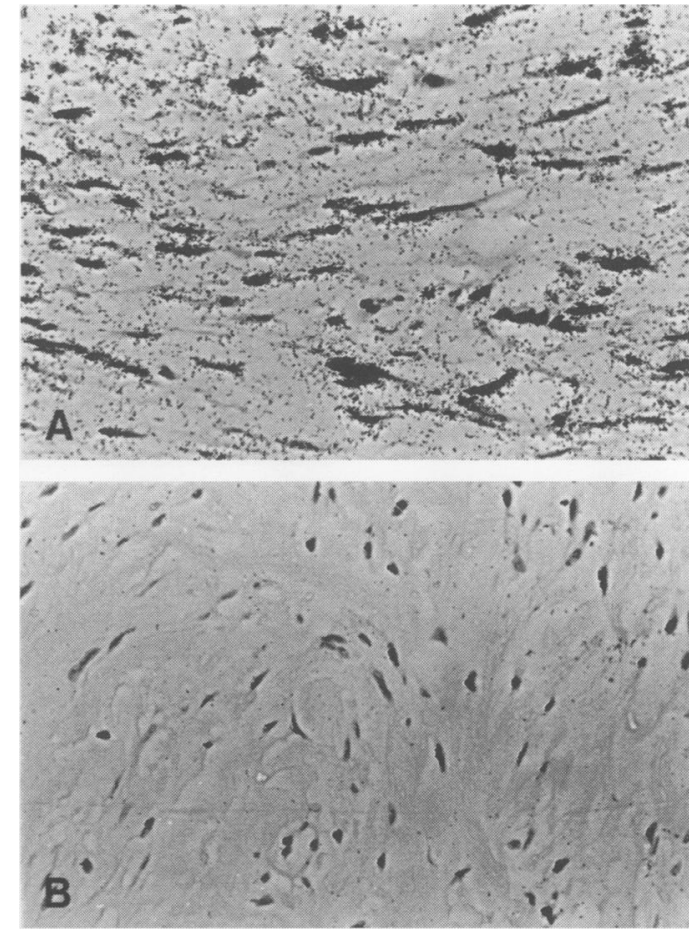

Figure $3 \quad P C P 1 m R N A$ abundance as assessed by in situ hybridisation in $(A)$ sternotomy scar six weeks after surgery; (B) section of six week old scar treated by RNase.

mature scar tissue (seven years after surgery) (fig 2C). In normal "healthy" skin, PCP 1 immunostaining was restricted to perivascular regions. In early scar tissue, both cellular and perivascular PCP 1 staining were present in biopsy specimens from all patients to varying degrees.

In situ hybridisation for PCP 1 messenger RNA (mRNA) revealed an increase abundance of this mRNA in cells in sections from scars six weeks after surgery (fig $3 \mathrm{~A}$ ), which was not observed in sections treated with RNase treated from scars obtained six weeks after surgery (fig 3B). In other experiments, the hybridisation signal was abolished by prehybridisation of sections with a 50 -fold excess of "cold" (unlabelled) antisense probe mixture of the same oligonucleotides before hybridisation. Conversely, pre-hybridisation with an excess unlabelled irrelevent probe did not abolish the signal. The expression of procollagen $1 \mathrm{mRNAs}$ using in situ analysis and their immunohistochemical localisation revealed consistency between mRNA and protein expression (figs $2 \mathrm{~A}$ and $3 \mathrm{~A}$ ).

TGF- $\beta$ protein was detected in scar tissue obtained six weeks after surgery (fig 4A). This staining was both intracellular and matrix associated. The TGF- $\beta$ immunostaining in six week old scar tissue was similar to, but slightly greater than, that in normal skin (fig 4B), but not as great as that observed in a model of an inflammatory skin disorder (tuberculin-heaf test) (fig 4C).

When the patients were ranked both according to the severity of the scar, as assessed by macroscopic appearance on the photographs and the abundance of PCP immunostaining, patients with scars which 
Figure 4

Immunohistochemical staining of TGF- $\beta$ in $(A)$ sternotomy scar six weeks after surgery; (B) normal skin; (C) biopsy specimen of a tuberculin-heaf test at five days.

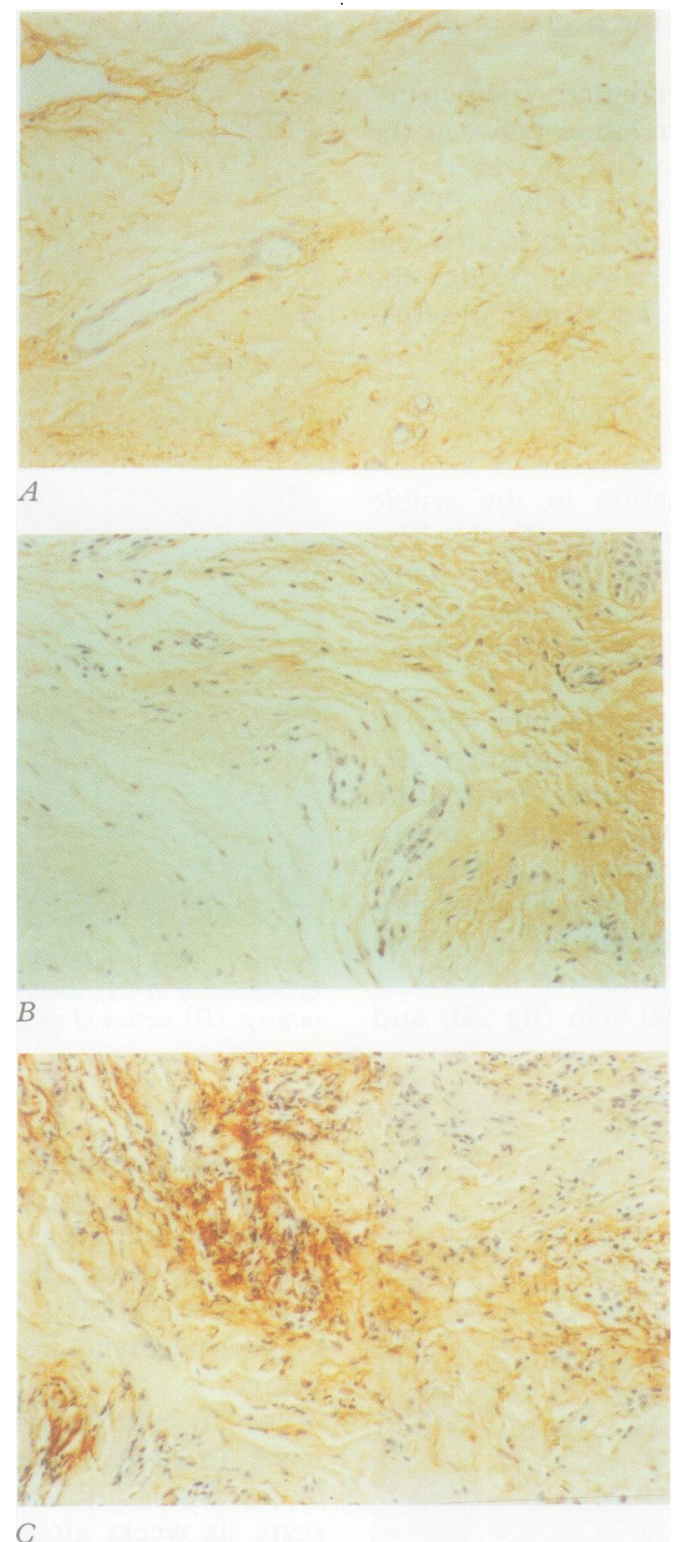

looked more severe had correspondingly greater procollagen 1 staining $\left(r_{s}=0.604, p<\right.$ 0.001 ) (fig 5). There was a particularly good correlation between the extent of PCP 1 staining and the severity of the scar in that only one of the 33 patients had a great abundance of PCP 1 immunostaining without a severe scar. Four of the 33 patients had a severe scar without intense PCP 1 immunostaining.

When the grade of cellular and perivascular PCP 1 immunostaining was compared between skin biopsy specimens from sites of

Figure 5 Relation

between ranking of patients according to severity of scar (vertical axis) or according to abundance of $P C P 1$ immunostaining (horizontal axis). Patient with most severe scar ranked first and patient with least ranked 33rd, with least ranked $33 r d$,
and similarly for $P C P 1$ immunostaining.

(Statistical analysis:

Spearman's rank

correlation coefficient.)

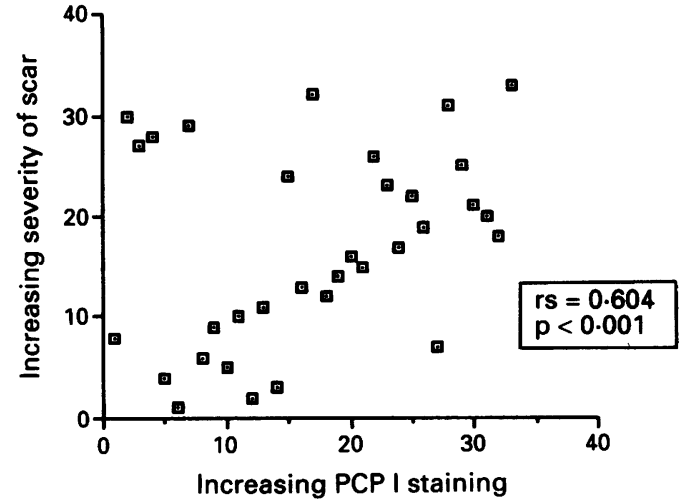

the scar where corticosteroid cream had been applied, and those from untreated regions of the scar, topical corticosteroids had no effect on PCP 1 immunostaining (figs 6A-D). In the first eight patients, biopsy was performed 48 hours after the application of one dose of topical corticosteroid. This was associated with a decrease by one grade in cellular PCP 1 staining in four patients and an increase in three patients (fig 6A). Similarly, perivascular staining decreased in three patients, increased in two patients, and remained unchanged in three patients (fig 6B).

In the second 25 patients, biopsy of both treated and untreated sites was performed after seven days of twice daily application of corticosteroid cream. Corticosteroids had no effect on cellular or perivascular PCP 1 staining. There was a decrease in cellular staining by one grade in nine patients, an increase by one grade in nine patients, and no change in seven patients (fig 6C). After treatment with corticosteroids, there was a reduction by one grade in perivascular PCP 1 staining in five patients, no change in the PCP 1 staining in 13 patients, and increases in staining by one grade in four patients, two grades in two patients and three grades in one patient (fig 6D). PCP 1 mRNA in situ hybridisation was performed in four pairs of samples on biopsy specimens from scars with or without seven days of prior treatment with topical corticosteroids, and no difference in the abundance of PCP mRNA was observed between treated and control tissues.

\section{Discussion}

This study documented the biochemical events in sternal scars six weeks after sternotomy. Immunohistochemical staining revealed an increase in both intracellular and perivascular staining for type 1 procollagen in the dermis, and in situ hybridisation confirmed that cells had an increased abundance of collagen mRNA. By comparison, normal healthy skin showed no evidence of cellular production of type 1 procollagen, some perivascular staining of PCP 1 , but a very low abundance of collagen mRNA. In mature scar tissue seven years after surgery, there was no PCP 1 staining, suggesting that the active fibrotic process had ceased. The degree of scarring as assessed macroscopically from photographs and PCP 1 immunostaining was variable, but correlated one with the other. This study thus extends observations which have already identified collagen mRNA in keloid tissue, ${ }^{20-22}$ as this is the first study identifying a biochemical correlate with the macroscopic severity of scarring. This link between the biochemical events in the scar and the macroscopic appearances, supports the approach of developing treatments against components of the fibrotic response, in that the data support the assumption that preventing new collagen formation is likely to reduce the severity of scarring.

Corticosteroids offer potential as agents to prevent excessive scarring. With their potent anti-inflammatory actions, they are likely to 
Figure 6 Number of patients demonstrating a change in the grade of cellular $(A$ and $C)$ or perivascular ( $B$ and $D)$ $P C P 1$ immunostaining after 48 hours ( $A$ and $B)$ or seven days $(C$ and $D)$ of topical corticosteroid treatment.
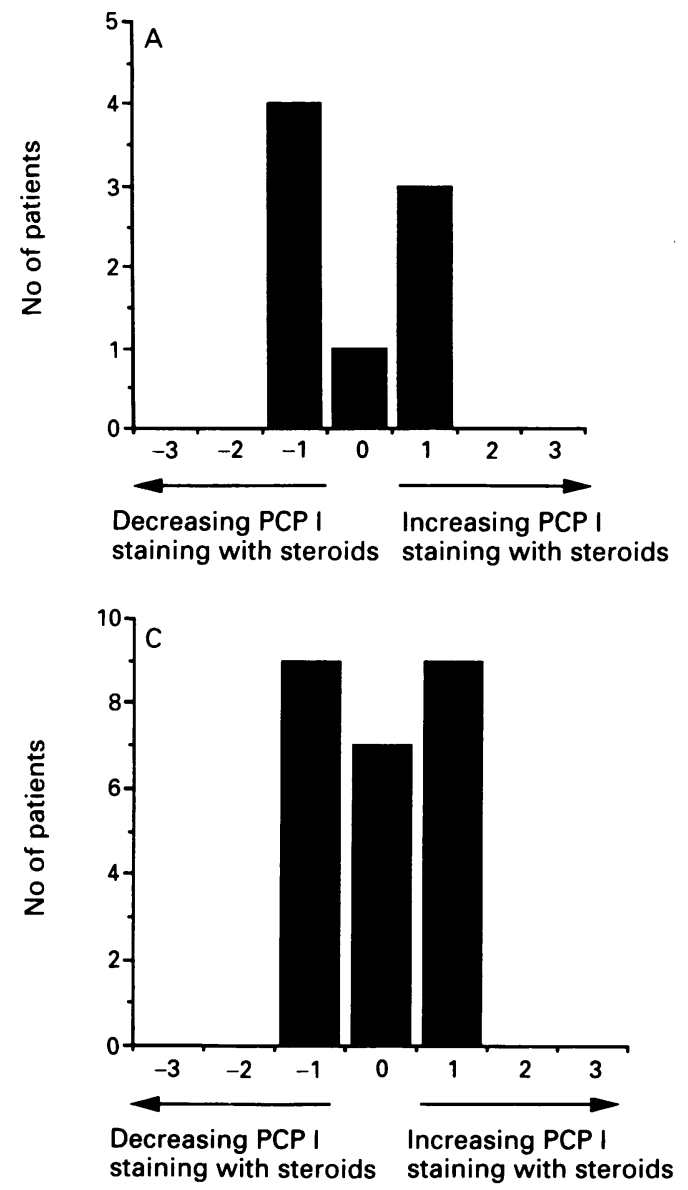

be effective in preventing the early inflammatory phase, and it has long been known that steroids prevent the formation of granulation tissue. ${ }^{23}$ When administered immediately after injury, indices of fibrosis are reduced. When applied within 24 hours to a skin blister, corticosteroids reduced the abundance of PCP 1 production by $75 \%$ after one day and $92 \%$ after two days. ${ }^{13}$ Corticosteroids have also been shown to inhibit the transcription of collagen in cultured fibroblasts and there is a glucocorticoid responsive element in the $5^{\prime}$ upstream non-coding region of the type 1 procollagen $a$ gene. ${ }^{24}$ However, in clinical practice corticosteroids have not been universally effective in the treatment of established hypertrophic scars. Optimal treatment may require excision with intraoperative steroids. ${ }^{25}$ The present study also suggests that in an established scar that is six weeks old, topical corticosteroids do not appreciably reduce collagen production. Thus, a single application of steroid cream over 48 hours and repeated applications over seven days did not significantly alter the perivascular or cellular concentration of procollagen 1 nor the abundance of collagen mRNA. One possible explanation is that adequate concentrations of corticosteroid were not absorbed. Although clobetasol is one of the most potent topical corticosteroids, the extent of skin penetration after topical application is poorly defined. Penetration into and through the epidermis is suggested by the work of Harding et $a l^{26}$ who documented vasoconstriction of normal skin
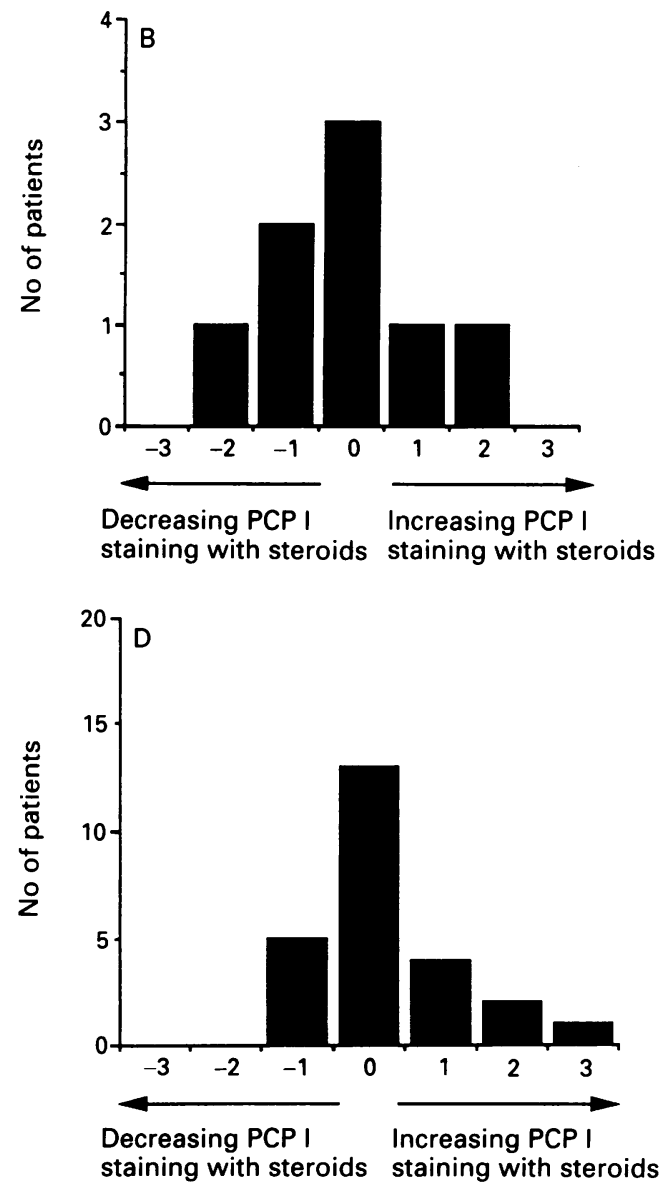

following application of clobetasol proprionate in propylene glycol as carrier (as was the case in the present studies). Other studies measuring subcutaneous adipose blood flow in normal skin have failed to demonstrate any effect attributable to clobetasol. ${ }^{27}$ The evidence of skin penetration in dermatoses is clearer. When applied to psoriatic skin, clobetasol proprionate has been associated with a reduction in circulating cortisol $^{28}$ and detectable plasma clobetasol concentrations. ${ }^{29}$ We were unable to find published data on the absorption into hypertrophic scars. In future studies injection of longer acting corticosteroids into the scar will be assessed.

Much of the published information comes from keloid scars which by definition continue to hypertrophy 12 months or more after the wound. ${ }^{1}$ We do not know what proportion of the scars in the present study will become keloid scars. However, information from fibroblasts from keloid scars offers an alternative hypothesis to explain the lack of effect of topical steroids observed in the present study. In this hypothesis fibroblasts lose their requirement for exogenous growth factors and become relatively resistant to exogenous inhibition. This hypothesis is supported by a number of pieces of evidence. Firstly, the abundance of TGF- $\beta$ in our scar biopsy specimens was less than that observed in biopsy specimens of the inflammatory skin lesion occurring five days after a tuberculin-heaf test, whereas the PCP 1 abundance was much greater in the six week old scars. Secondly, 
Babu et $a^{30}$ have shown that, unlike normal fibroblasts, keloid fibroblasts do not increase total protein synthesis in response to TGF- $\beta$, although under certain conditions keloid fibroblasts increase fibronectin production in response to TGF- $\beta$ compared with normal cells. Thirdly, others have shown that hydrocortisone resulted in $60 \%$ inhibition of collagen synthesis in fibroblasts from normal scars but no reduction in cells from keloid scars. ${ }^{31} 32$ Fourthly, keloid fibroblasts in culture are refractory to inhibition of DNA synthesis by phorbol esters and have reduced sensitivity to prostaglandin E2. ${ }^{33}$ These differences between normal and keloid fibroblasts may be due to changes in receptors in that keloid fibroblasts have reduced phorbol ester binding affinity, ${ }^{33}$ or altered enzyme activity-for example, keloid fibroblasts have higher G6PDH activity under oxygen saturation conditions than normal cells. ${ }^{34}$ Fifthly, at least a proportion of fibroblasts from keloids have increased type 1 procollagen mRNA, rates of procollagen production, and decreased rates of collagen degradation, compared with fibroblasts from control skin. ${ }^{35} 36$

Therefore, early events after a wound probably involve an inflammatory phase characterised by the presence of the inflammatory cytokines. Patients with a predisposition to keloid formation may have mononuclear cells with an increased capacity to produce inflammatory cytokines such as interleukin-6, tumour necrosis factor $a$ and interferon $\beta .^{37}$ Growth factors are produced for fibroblasts, such as platelet derived growth factor $\beta$ and TGF- $\beta$. Studies which have involved supplementing the growth factors at this stage suggest that platelet derived growth factor containing the $\mathrm{B}$ subunit is responsible for recruiting procollagen 1 containing fibroblasts while TGF- $\beta 1$ results in increased intracellular concentrations of procollagen $1 .^{738-41}$ The effects of adding corticosteroids at this early stage can also be partly overcome by addition of TGF- $\beta$ to the wound. ${ }^{40}$ Once the scar is established, the fibroblasts continue to be active for a long time in the absence of an inflammatory phase or evidence of increased growth factors. In our study the duration of the active fibrotic phase was surprisingly long. Biopsy specimens taken from patients 11 months and two and a half years after sternotomy both showed PCP 1 staining which were grades +++ and + , respectively. However, six and seven years after surgery there was no PCP1 staining. As diverse patterns of macroscopic appearances and PCP1 staining were established by six weeks, it seems that the events which determine whether the fibroblasts in the scar are going to switch to a keloid-like phenotype, resulting in a hypertrophic scar, occur prior to six weeks. These events may relate to the nature or extent of the inflammatory phase. It is attractive to hypothesise that fibroblasts bathed in high concentrations of inflammatory cytokines and growth factors during this early phase remain hyperactive and thus contribute to more florid scar formation. This concept of a fibroblast which becomes persistantly active in response to exogenous stimuli, and passes this capacity on to subsequent generations despite repeated replication has been suggested in scleroderma and lung fibrosis..$^{42}$

This study was supported by grants from the Medical Research Council and the British Lung Foundation. We thank Dr Foale and Mr Stanbridge (at St Mary's Hospital), and Professor Taylor and $\mathbf{M r}$ Keogh (at The Hammersmith Hospital), for allowing us to study their patients.

1 Harding Rains AJ, David Ritchie H. The healing and management of wounds. In: Bailey and Love's $A$ short practice agement of wounds. In: Bailey and Love's A short pra

2 Ketchum LD, Cohen ID, Masters FW. Hypertrophic scars and keloids. Plast and Reconstruct Surg 1974;53:140-51.

3 Kovacs EJ. Fibrogenic cytokines: The role of immune mediators in the development of scar tissue. Immunol Today 1991;12:17-23.

4 Prockop DJ, Kivirikko KI, Tuderman L, Guzman NA The biosynthesis of collagen and its disorders (first of two parts). N Engl F Med 1979;301:13-23.

5 Prockop DJ, Kivirikko KI, Tuderman L, Guzman NA. The biosynthesis of collagen and its disorders (second of two parts). N Engl ₹ Med 1979;301:77-85.

6 Martinez-Hernandez A. Repair, regeneration and fibrosis In: Rubin E, Farber JL, eds. Pathology. Philadelphia: J B Lipincott, 1994:81-93.

7 Pierce GF, Brown D, Mustoe TA. Quantitative analysis of inflammatory cell influx, procollagen type 1 synthesis, and collagen cross-linking in incisional wounds Influence of PDGF-BB and TGF-Beta 1 therapy. $\mathcal{F} \mathrm{Lab}$ Clin Med 1991;117:373-81.

8 Prockop DJ. Collagen biochemistry-design of agents to inhibit excessive accumulation of collagen during wound repair. In: Dineen $\mathrm{P}$, ed. The surgical wound. Philadelphia: Lea \& Febiger, 1981:97-109.

9 Cohen IK, McCoy BJ. Keloid; Biology and treatment. In: Dineen P, ed. The surgical wound. Philadelphia: Lea \& Febiger, 1981:123-31.

10 Craig RDP, Schofield JD, Jackson DS. Collagen biosynthesis in normal and hypertrophic scars and keloid as a function of the duration of the scar. $\mathrm{Br} F$ Surg 1975;62:741-4.

11 Stryer L. Connective tissue proteins. Biochemistry. New York: WH Freeman \& Co., 1988:269-73.

12 McDonald JA. Broekelmann TJ, Matheke ML, Crouch E, Koo M, Kuhn C. A monoclonal antibody to the carboxyterminal domain of procollagen type 1 visualises boxyterminal domain of procollagen type 1 visualises 78:1237-44.

13 Griswold ML. Effect of adrenal cortical preparations on scar hypertrophy. Plast Reconstruct Surg 1954;13:454-61.

14 Oikarinen A, Autio P, Kiistala U, Risteli L, Risteli J. A new method to measure type I and III collagen synthesis in human skin in vivo: Demonstration of decreased collagen synthesis after topical glucocorticoid synthesis. f Invest Dermatol 1992;98:220-5.

15 Warburton MJ, Fernes SA, Hughes CM, Sear CHJ, Rudland PS. Generation of cell types with myoepithelial and mesenchymal phenotypes during the conversion of rat mammary tumor epithelial stem cells in to elongated rat mammary tumor epithelial ster

16 Taylor M, Cook T, Pearson C, Risdon RA, Peart S. Renin messenger RNA localisation in congenital mesoblastic nephroma using in situ hybridization. $\mathcal{F}$ Hypertension 1989;7:733-40.

17 Bernard MP, Chu ML, Myers JC, Ramirez F, Eikenberry EF. Nucleotide sequences of complementary deoxyribonucleic acids for the Proal chain of human type 1 Procollagen. Statistical evaluation of structures that are conserved during evolution. Biochemistry 1983;22: 5213-23.

18 Naish SJ, ed. Handbook of immunochemical staining methods. California: Dako Corporation, 1989.

19 Siegel S. Nonparametric statistics for the behavioural sciences. Tokyo: McGraw-Hill Book Co., 1956.

20 Lee KS, Song JY, Suh MH. Collagen mRNA expression detected by in situ hybridization in keloid tissue. f Dermatol Sci 1991;2:316-23.

21 Peltonen J, Hsiao LL, Jaakkola S, Sollberg S, Aumailley $M$, Timpl $R$, et al. Activation of collagen gene expression in keloids: co-localization of type I and VI collagen and transforming growth factor beta $1 \mathrm{mRNA}$. F Inves Dermatol 1991;97:240-8.

22 Sollberg S, Peltonen J, Uitto J. Combined use of in situ hybridization and unlabelled antibody peroxidase antiperoxidase methods: simultaneous detection of type peroxidase methods. simultaneous detection of type procollagen mRNAs and factor VIII-related antito

23 Baker BL, Whitker WL. Interference with wound healing baker $\mathrm{BL}$, Whitker WL. Interference with wound healing
by local action of adrenal cortical steroids. Endocrinology by local action of

24 Perez JL, Shull S, Gendimenico GJ, Capetola RJ, Mazik JA, Cutroneo KR. Glucocorticoid and retinoid regula$\mathrm{JA}$, Cutroneo KR. Glucocorticoid and retinoid regula-
tion of alpha 2 type 1 procollagen prometer activity. $\mathcal{f}$ Cell Biochem 1992;50:26-34. 
25 Tang YW. Intra- and postoperative steroid injections for keloids and hypertrophic scars. Br F Plast Surg 1992 45:371-3.

26 Harding SM, Sohail S, Busse MJ. Percutaneous absorption of clobetasol proprionate from novel ointment and cream formulation. Clin Exp Dermatol 1985;10: 13-20.

27 Peterson LJ, Sindrup JH, Kristensen JK. Subdermal penetration of topically applied clobetasol proprionate in ointment base through intact human skin: lack of effect on subcutaneous adipose tissue blood flow. $\mathcal{F}$ Dermatol Sci 1992;3:42-5.

28 Gip L, Hamfelt $A$. Studies on the efficacy and adrenal effects of Diproline ointment $0.05 \%$ and Dermovate ointment $0.05 \%$ in patients with psoriasis or other dermatosis. Cutis 1984;33:215-24.

29 Hehir M, du Vivier A, Eilon L, Danie MJ, Shenoy EVB. Investigation of the pharmacokinetics of clobetasol proprionate and clobetasone butyrate after a single application of ointment. Clin Exp Dermatol 1983;8:143-51.

30 Babu M, Diegelmann R, Oliver N. Keloid fibroblasts exhibit an altered response to TGF-Beta. F Invest Dexhibit an altered resp

31 Russell JD, Russell SB, Trupin KM. Differential effects of hydrocortisone on both growth and collagen metabolism of human fibroblasts from normal and keloid tissue. $f$ Cell Physiol 1978;97:221-3.

32 Russell SB, Trupin JS, Myers JC, Broquist AH, Smith JC, Myles ME, et al. Differential glucocorticoid regulation of collagen mRNAs in human dermal fibroblasts. $\mathcal{f}$ Biol Chem 1989;264:13730-5.

33 Myles ME, Russell JD, Trupin JS, Smith JC, Russell SB Keloid fibroblasts are refractory to inhibition of DNA synthesis by phorbol esters. Altered response is accompynthesis by phorbol esters. Altered response is accompanied by reduced sensitivity to prostaglandin E2 and altered down-regulation of phor
Biol Chem 1992;267:9014-20.

34 Sit KH, Lau YK, Aw SE. Differential oxygen sensitivities in G6PDH activities of cultured keloid and normal skin dermis single cells. F Dermatol 1991;18:572-9.

35 Diegelmann RF, Cohen IK, McCoy BJ. Growth kinetics and collagen synthesis of normal skin, normal scar and keloid fibroblasts in vitro. Cell Physiol 1979;98:341-6.

36 Abergel RP, Pizzuro D, Meeker CA, Lask G, Matsuoka LY, Minor RR, et al. Biochemical composition of the connective tissue in keloids and analysis of collagen
metabolism in keloid fibroblast cultures. $\mathcal{f}$ Invest metabolism in keloid

37 McCauley RL, Chopra V, Li YY, Herndon DN, Robson MC. Altered cytokine production in black patients with keloids. F Clin Immunol 1992;12:300-8.

38 Mustoe TA, Pierce GF, Thomason A, Gramates P, Sporn MB, Deuel TF. Accelerated healing of incisional wounds in rats induced by transforming growth factorbeta. Science 1987;237:1333-5.

39 Pierce GF, Mustoe TA, Senior RM. In vivo incisional wound healing augmented by platelet-derived growth factor and recombinant c-sis gene homodimeric proteins. F Exp Med 1988;167:974-87.

40 Pierce GF, Mustoe TA, Linglebach J, Masakowski VR, Gramates $P$, Deuel TF. Transforming growth factor beta reverses the glucocorticoid-induced wound healing
deficit in rats. Proc Natl Acad Sci USA 1989;86:2229-33. 41 Mustit in rats. Proc Natl Acad Sci USA 1989;86:2229-33. Mustoe TA, Purdy J, Gramates P, Deuel TF, Thomason
A, Pierce GF. Reversal of impaired wound healing in irradiated rats by platelet-derived growth factor-BB: requirement of an active bone marrow. $\mathrm{Am} f \mathrm{Surg}$ 1989;158:345-50.

42 Bordin S, Page RC, Narayanan AS. Heterogeneity of normal human diploid fibroblasts: isolation and characterization of one phenotype. Science 1984;223:171-3.

43 Jordana M, Schulman J, McSharry C, Irving LB, Newhouse MT, Jordana G, et al. Heterogeneous prolif-
erative characteristics of human adult lung fibroblast lines and clonally derived fibroblasts from control and fibrotic tissue. Am Rev Respir Dis 1988;137:579-84. 